Iberian Journal of the History of Economic Thought

ISSN: 2386-5768

\title{
La primera guerra mundial y la conducta económica del Estado en el pensamiento militar en Argentina
}

Aldo Avellaneda ${ }^{1}$

Recibido: 22 de agosto de 2018 / Aceptado: 20 de febrero de 2019

Resumen. Los estudios sobre el pensamiento económico en América Latina no se han detenido en los cuadros militares como actores sociales relevantes a lo largo de casi todo el siglo XX. En este artículo trato de rastrear el surgimiento del interés y la preocupación por el comportamiento económico del Estado en las reflexiones militares. Identifico la Primera Guerra Mundial como una coyuntura crítica que introduce la pregunta por la economía y que viene de la mano de la convicción en el pensamiento militar de que en adelante las guerras serán industriales o no serán. Por medio de un repaso de diversas publicaciones militares — revistas, libros y memorias ministeriales - intento seguir el recorrido de las reflexiones, que parten del interés por la propia potencia militar, pero que rápidamente pasan a considerar la posibilidad y los beneficios de un Estado que apoye una planificación industrial.

Palabras clave: Pensamiento Militar, Primera Guerra Mundial, Industria.

Clasificación JEL: B15, L6, N46

\section{[en] First World War and State's economic behavour in Argentina's military thought}

Abstract. Economic Thought' Studies in Latin America have not paid attention to military cadres as relevant social actors throughout most of the 20th century. In this article I try to trace the emergence of interest and concern for the economic behavior of the State in military reflections. I identify the First World War as a critical episode which introduces the question on the state economy. It comes from the hand of a conviction in military thought that from now on wars will be industrial or they won't. Through a review of various military publications - journals, books and ministerial reports - I try to follow the course of their reflections, which start from the interest for the military power itself, but quickly come to consider the very possibility and the benefits of a State that support industrial planning.

Keywords: Military Thought, First World War, Industry.

JEL classification: B15, L6, N46

Sumario: 1. Introducción. 2. Rasgos del protoeconomicismo en el pensamiento militar. 3. En el principio fue la guerra. 4. El acero, el combustible y su organización. 5. Economía y conducta estatal. 6. Conclusión. Bibliografía.

Cómo citar: Avellaneda, A. (2019) "La primera guerra mundial y la conducta económica del Estado en el pensamiento militar en Argentina", en Iberian Journal of the History of Economic Thought 6(1) (2019), 17-35.

\section{Introducción}

Las narrativas sobre la historia del pensamiento económico en América Latina parecen haber tomado, como su contraparte europea, dos carriles fundamentales. Por un lado, han seguido el derrotero de corrientes de pensamiento, siendo las más visitadas los enfoques de la dependencia, del desarrollo, con sus núcleoscuerpo identificatorios como la CEPAL o el estructuralismo latinoamericano. Muy ligado a esto, se han desarrollado monografías sobre la trayectoria intelectual de algunos referentes, como Raúl Prebisch, Vannia Bambirra, Gunder

\footnotetext{
1 Centro de Estudios Sociales, UNNE. CONICET.
} 
Frank o Celso Furtado, entre muchos otros ${ }^{2}$. Por otro lado, un acercamiento más empírico a los saberes expertos ha seguido la trayectoria de economistas, juristas o políticos que se han desempeñado en ámbitos públicos o privados y que lo han hecho tratando de sistematizar sus perspectivas ${ }^{3}$.

A cierta distancia de ambos desarrollos, en este artículo aspiro a caracterizar las reflexiones económicas de unos actores sociales y políticos de importancia en la Argentina: los cuadros militares (oficiales subalternos y superiores) del ejército. Resulta sorprendente y llamativo que este asunto no haya sido materia de estudios, más allá de muy contados casos (Daikova, 2014; Forte, 2003, parcialmente Yelpo 1987). A partir de 1930 y hasta los primeros años de la década de los ochenta, el estado argentino fue conducido por elencos gubernamentales provenientes de las filas militares o estuvo bajo un régimen de tutelaje más o menos directo según los casos. Considero que la ausencia de trabajos sobre el pensamiento económico en el mundo militar puede sostenerse solamente si se asume alguna de las tres siguientes hipótesis. La primera es que tales cuadros no tenían planteamientos económicos singulares de ningún tipo; la segunda es que, de tenerlos, por alguna razón no tenían presencia en las políticas efectivamente implementadas. La tercera, que podría tomarse como una variante de la primera, es que el ideario económico de los cuadros militares es algo que traspasa su propio mundo y los vincula a otros sectores y actores sociales, y entonces lo que toca estudiar es a estos últimos. Este trabajo parte por distanciarse de las dos primeras hipótesis y plantea algunas consideraciones a la tercera.

De la suposición de que el estatus social de la oficialidad del ejército ubicaba a los cuadros medios y superiores en una zona de intercambio e interdependencia con las élites políticas y económicas de su tiempo, se ha deducido más tácita que explícitamente la existencia de una comunión de horizontes culturales, económicos o políticos. Sin confrontar de modo general con esta idea y aun manifestando la necesidad de nuevos trabajos que traten de reconstruir las redes de socialización que permeaban el mundo militar (tanto hacia la aristocracia como al campo popular), creo que, puesto a prueba sobre un caso macizo y concreto como lo es el de la emergencia del interés por la economía estatal, podrían esbozarse trayectorias singulares ${ }^{4}$.

Me interesa puntualmente elaborar la genealogía de una preocupación específica, la de la racionalidad militar con respecto a la conducta económica del Estado. ¿En qué momento y en relación a qué factores los cuadros militares vincularon el Estado, más precisamente su comportamiento económico, en los diagnósticos de su propia situación? ¿Bajo qué coyuntura el pensamiento militar comenzó a mostrar interés en la economía estatal? Respecto a esto, la hipótesis que trato de recorrer es que la primera guerra mundial resultó un factor clave que dislocó el plano de ordenamiento sobre el cual el pensamiento militar había hasta allí dado sentido al contexto nacional e internacional. La guerra resultó un acontecimiento que abrió el campo de reflexiones a nuevas preguntas, diagnósticos y preocupaciones primero, luego a tímidos ejercicios de comprensión y casi en paralelo a los primeros ensayos de planificación. $\mathrm{Y}$ en este punto me detengo, pues no pretendo desarrollar las vicisitudes de las reflexiones económicas en el ejército para comprender la dirección de las políticas públicas históricamente implementadas. Este es un trabajo enteramente orientado hacia la historicidad de unas formas singulares de pensamiento.

El artículo se divide en tres apartados. En el primero señalo algunas reflexiones tempranas y rudimentarias por parte de los cuadros militares en relación a temas económicos o cercanos. Seguidamente expongo la centralidad del carácter industrial de la primera guerra en las publicaciones militares de finales de la

Ver, entre otros Baracs et al., 1980; Mallorquín, 2014; Love, 1990, 2008; Orestes, 1997. Para el pensamiento económico a principios del siglo XX en Argentina, ver Audino, 2004, Caravaca, 2011, 2016; Wozniak, 2014. Hacia las últimas páginas vuelvo sobre esta literatura.

3 Sin mencionar los trabajos sobre el mismo Prebisch, existe una marcada atención en esta perspectiva sobre el desempeño de intelectuales-funcionarios argentinos como Federico Pinedo y Alejandro Bunge (Caravaca, 2005; Gonzalez Bollo, 2012; Jáuregi y Regalsky, 2003; Vicente 2013). Para una estrategia comparativa de intelectuales-funcionarios latinoamericanos, ver Caravaca y Espeche, 2016.

4 Aún en la historiografía militar, la cuestión de la racionalidad económica es a la vez una de las carencias más notorias y el lugar de los supuestos y las hipótesis afirmadas con más firmeza como poco controladas. Se pueden ver para esto los clásicos Scenna (1980), Rouquié $(1984,1986)$ y Potash (1971), pero también trabajos recientes como el de García Molina (2010). Tampoco se observa un detenimiento en la primera guerra como episodio nodal en el estudio de las formas de pensamiento de los cuadros militares (pero también pueden ser sus trayectorias profesionales y modos de organización) (Ver Cornut, 2018). 
segunda década y principios de la tercera y el modo en que esto comenzó a tener cierto efecto en la consideración de algunos aspectos de la política económica local. Las reflexiones de Enrique Mosconi y Domingo Savio - los dos íconos del pensamiento industrialista-militar- son el objeto del tercer apartado. Trato de justificar aquí que más allá de la singularidad de sus estilos y de las posiciones que ocuparon, sus trayectorias deben comprenderse en el marco de un modo de problematización de la serie Ejército-Estado-Economía que resultaba algo regular en el mundo militar a finales de la década de 1920, mundo cuya entrada en una nueva era de guerras industriales era algo plenamente asumido. Por último, repaso algunas características centrales de estos modos de reflexión, en relación al carácter agroexportador de la economía argentina, el rol de la planificación económica, el juicio sobre los capitales públicos y privados, entre otros.

Si debido al tema y a los actores sociales cuyas formas de pensamiento se pretende relevar, este trabajo puede ser visto como una contribución tanto a la historiografía militar como al campo del pensamiento económico, estimo que sus aportes también podrían ser relevantes para el campo de la historia social y cultural más general, toda vez que los estudios sobre el impacto de la primera guerra en la Argentina, no parecen haber considerado hasta aquí, paradojalmente, los efectos recíprocos entre el mundo militar y la sociedad ${ }^{5}$.

\section{Rasgos del protoeconomicismo en el pensamiento militar}

Si se deja de lado el carácter regular y burocrático de algunas formas de reflexión económica en las primeras dos décadas del siglo XX, como los presupuestos del Ministerio de Guerra y su administración interna (Intendencia), hay solamente dos lugares en los que, si bien de una manera rudimentaria, el pensamiento militar se acercaba a regiones de reflexión y cálculo económico. Una de esas formas esta- ba relacionada con un problema republicano e impositivo a la vez. Junto a la sanción de la ley Roca-Ricchieri de 1901, se había fijado una "Tasa Militar", una suerte de impuesto que debían abonar todos aquellos que, correspondiéndole la edad para realizar el Servicio Militar Obligatorio (SMO), no lo hacían por estar exceptuados por algún motivo. Atascados entre el supuesto "ley justa es ley pareja" y la convicción derivada de que la excepción resultaba un privilegio, se había fraguado esta suerte de compensación monetaria anual para todos aquellos que no podrían ser cada año remitidos a los cuarteles. En la ley de 1901 la carga pesaba de modo progresivo todo a lo largo del servicio activo de los individuos, desde los diecinueve hasta los cuarenta y cinco años y se pagaba anualmente $-\mathrm{O}$, al menos, se la pensaba de ese modo-, al momento de la renovación de la excepción. Lo recaudado debía destinarse a construcciones militares y adquisición de campos de maniobras, a un fondo para la organización de las maniobras anuales, y en una quinta parte, a una caja de ayuda para viudas y huérfanos. A partir de 1905 se derivaron los fondos al "fomento al tiro ciudadano".

La obligatoriedad del SMO había sido considerada de este modo como un principio propio de recaudación, aunque exiguo, ya que la excepción era considerada a la vez como un perjuicio a la organización armada y un privilegio de los exceptuados. Únicamente estarían libres de pagar la Tasa Militar los "pobres de solemnidad", quienes — se esperaba- pudieran acreditar su pobreza con dos testigos y por escrito. Este principio de operatoria fiscal inmediatamente tuvo diagnósticos desalentadores, y no solamente porque las redes sociotécnicas -el grado de dispersión y encadenamiento de las instancias de control y las capacidades de lecto-escritura individuales presupuestas - parecen haber estado lejos de posibilitar un ejercicio de recaudación aceptable, sino porque para mitad de la segunda década los fondos pasaron a rentas generales, más allá del control de las propias instancias militares $^{6}$.

Junto a los efectos económicos de la guerra, los temas mayormente atendidos son la posición de la prensa, el aspecto "movilizador" de la guerra en las opiniones públicas y distintos sectores sociales (particularmente inmigrantes), y las estrategias diplomáticas. Pueden verse, entre otros, Albert (1988), Otero (2011), Tato (2008, 2011, 2014, 2017), así como los artículos de los números especiales de las revistas PolHis 14(7), coordinada por la misma autora e Iberoamericana XIV (53), al cumplirse cien años del inicio de la guerra.

6 Aun dando por sentado el carácter "inflado" de los números, sorprende que los cálculos no daban porcentajes tan exiguos, ya que por ejemplo entre 1913 y 1921 poco más del \%60 de los exceptuados había abonado la Tasa Militar (RM, 1921: 535-539). 
También en esa segunda década se esgrimieron algunas reflexiones que, enfatizando el principio impositivo de la medida, hacían jugar además otros presupuestos y razones. El general Munilla estaba en contra de la Tasa Militar debido a su blanco de aplicación, los exceptuados psicofísicos. Se trataba para él de "una multa impuesta al infortunio" (Munilla, 1916, 150). En su lugar proponía la aplicación del impuesto a los exceptuados por el azar, y no a los convalecientes. Teniendo en cuenta que la diferencia entre el número de enrolados y los que efectivamente concurrían a los cuarteles todos los años multiplicaba al número de los legalmente exceptuados, la posición era apoyada así en un doble fondo, tanto ético como impositivo ${ }^{7}$. Más allá de algunas repercusiones de estas reflexiones en la Revista Militar (RM), el tema tuvo una escasa atención en todo el periodo. Sin embargo, todos los proyectos de reclutamiento posteriores al de Roca-Ricchieri $(1905,1909,1918,1923)$ incluyeron la Tasa Militar como una maniobra de recaudación, aunque muy posiblemente su razón esté más en la penalización de las excepciones que en su costado económico-impositivo ${ }^{8}$.

El segundo campo de aplicación de algunas reflexiones económicas fueron los proyectos sobre las requisiciones de guerra. En este caso y a diferencia de la Tasa Militar, la preocupación económica no derivaba de la inquietud de política doméstica por hacer decrecer los incentivos de la población masculina para sortear el SMO, sino más bien con el hecho puntual y macizo de la guerra y las vías de afrontarla con éxito. Desde el final de la guerra ruso-japonesa y presintiendo - ya que no era objeto de reflexión aún- el panorama de las "guerras integrales", "guerras totales" o "guerras industriales", la cuestión de los recursos extra militares con los que entrar en combate pasará tímidamente a formar parte del paisaje reflexivo de los cuadros militares, contando para ello, claro, con los antecedentes de algunos ejércitos europeos.

La ley de requisición era en realidad para los cuadros militares la posibilidad de un gran censo militar. Si bien contribuía a estipular ju- rídicamente de antemano los modos en que el ejército podría disponer de bienes comestibles, inmuebles, animales, medios de transporte etc. en situación de guerra declarada, la mayor ventaja estaba en el conocimiento que se podría obtener con antelación de los insumos existentes a fin de un mejor pertrechamiento y movilidad del ejército. Por esa razón era reputado como el medio idóneo y necesario para pasar de un pie de paz a un pie de guerra.

Se trataba de saber los medios de movilidad y alojamiento con que se cuenta y en qué parte del país, quiénes son sus propietarios y cuáles son sus características; el tipo de ganado, su edad, su nivel de adiestramiento y sus pelos; también las poblaciones fronterizas, los baqueanos más reputados y sus domicilios, el detalle de las vías férreas y navegables junto a sus sistemas de transporte - empresas, concesiones-, etc. Con respecto a esto último, se pensaba incluso que los municipios podrían "confeccionar un estado que demuestre el número de vehículos, la trocha, carga máxima, si son con elásticos, ruedas, número de animales necesarios para su conducción y cantidad de rodados por tipos" (RM, enero de 1914: 16). El conocimiento de estos recursos resultaba una parte especial de la preparación para la guerra. El proyecto de organización militar del general Aguirre en 1909 contenía por primera vez una sección destinada al tema, y posteriormente fue retomado por el general Uriburu en 1914 para un nuevo tratamiento parlamentario, ya con el clima de la Gran Guerra encima. Lo importante es que aquí y por primera vez la guerra expandía el registro de la reflexión económica al tiempo de paz. De todas maneras, no dejaba de ser un recurso excepcional y ciertamente no produjo ningún tipo de modalidad reflexiva sostenida, siquiera como la Tasa Militar.

\section{En el principio fue la guerra}

Un artículo del coronel Zerda en el número de agosto de 1916 de la RM desató súbitamente un múltiple intercambio sobre el tema del SMO en el segundo semestre de ese año y el

Munilla, ob. cit.,145-154.

Otro indicador de la poca variación que tuvo la Tasa Militar como política efectiva es que aún un informe de un general alemán de 1921, en el que evaluaba dos proyectos de organización militar en estudio por esos años, señalaba como falla la falta de progresividad en la medida, aunque aducía que ello podría ser casi imposible en la Argentina, puesto que no cobraba impuestos directos a la renta (RM, abril de 1921: 386). 
primero del siguiente 9 . En un contexto de fuertes restricciones de la economía estatal, que se traducía entre otras cosas en el licenciamiento temprano de los contingentes de conscriptos, el escrito proponía la reducción del servicio militar a seis meses y a su vez la duplicación del número de individuos incorporados. Argumentaba que esto podría hacerse a condición de pasar la instrucción física e intelectual de los jóvenes al Ministerio de Instrucción Pública - con programas elaborados por cuadros militares - y ocupando esos 180 días en una preparación exclusivamente militar. Si bien lo medular del debate estaba vinculado a la función del ejército y las expectativas de sus cuadros respecto a los jóvenes conscriptos en un clima de excitación debido a la guerra en Europa, existe en este intercambio un pequeño desplazamiento en algunas percepciones que remiten en principio al dominio de la estrategia militar, pero que tendrán vastas consecuencias respecto al modo de pensar el rol económico del Estado.

En su segunda y última intervención en aquel intercambio, el coronel Zerda, respondiendo al mayor Diana sobre la viabilidad o no de la instrucción militar en seis meses, señalaba a éste la justicia de sus razonamientos "si nos encontráramos en Europa, en donde los países han hecho de la guerra la principal de sus industrias" (RM, noviembre de 1916, 631). Sobre la superficie de las diferencias existía entre los articulistas una de singular relevancia: el presupuesto de una necesaria organización militar diferente entre la Argentina y los países europeos. Esto, que había sido parte de los implícitos consensuados en el pensamiento militar a finales del siglo XIX y principios del XX, comenzaba a cambiar. Hasta aquí se pensaba que en Europa, por historia, relaciones interestatales, animosidad de sus pueblos e incluso una litigiosidad consuetudinaria, los países estaban condenados a paralelizar su organización económica con su organización guerrera y que aquí y en toda América del Sur, en cambio, el deber de los países era "civilizarse robusteciendo la propia nacionalidad, aumentar su población en sus vastos territorios desiertos, y después, enriquecerse por medio del trabajo honrado" (RM, noviembre de 1916, 632). La percepción de esta diferencia había sido el punto de sostén tanto para las críticas y los apoyos al proyecto Roca- Ricchieri —más allá de las diferencias, todos parecían compartir la necesidad de no "copiar" o "implantar" nada que no responda a las características o necesidades del país-, para los reglamentos tácticos de la segunda mitad de la primera década, pero también para las críticas del partido socialista o de algún sector de la prensa a la ley de requisiciones o a los intentos de organización de maniobras.

Ahora bien, a excepción del coronel Zerda en este debate y cada vez con mayor fuerza en los próximos años, la percepción de esta diferencia se irá borrando paulatinamente. $\mathrm{Y}$ en ello, el carácter económico-tecnológico de la guerra y el rol de diversas instancias estatales en su organización, jugarán un papel central. A partir de 1918, la sección de "Noticias Militares" de la RM comenzó a cubrirse casi en su totalidad con escritos breves respecto a las nuevas técnicas y la descripción de algunos combates. Para 1920 y 1921 la guerra había trascendido el ámbito de esta sección así como de la mera descripción de los artefactos ${ }^{10}$.

Los cuadros militares argentinos comenzaban a acusar recibo de la importancia de los artefactos tecnológicos en la Gran Guerra, pero también de las tácticas de defensa y ataque, la logística y las comunicaciones. Los manuscritos referidos a uno u otro de estos aspectos se reproducen con ritmo casi frenético desde inicios de la década de 1920. Al impacto de la guerra en sí misma, le siguió el impacto de su

\footnotetext{
Pueden verse los artículos del coronel Zerda "Reflexiones sobre la ley 4707" (RM, agosto de 1916, 449-453), la respuesta del mayor Diana "A propósito de algunas reflexiones sobre el servicio obligatorio" (RM, septiembre de 1916: 550-557), una intervención del capitán Gaspar Zoria, "Los efectivos en paz y la duración del servicio en infantería” (RM, septiembre de 1916, 576-585); la réplica del coronel Zerda, "Otra vez la ley 4707” (RM, noviembre de 1916: 633-638); una intervención del capitán Levene, "Infantería" (noviembre de 1916, 666-669), y una última intervención del capitán Galarce, "Algo más sobre nuestro servicio obligatorio" (RM, diciembre de 1916, 736-741).

10 Existe un estudio temprano del capitán Jáuregui, de mediados de 1910 aunque publicado en la RM entre los meses de febrero y marzo de 1915 que, apoyándose en lo fundamental en las características de la guerra ruso-japonesa, aspira a enunciar una nueva era en cuanto a táctica de guerra. En la primera entrega de "Transformación de la táctica en los últimos cuarenta años. La guerra de zapa", señala: "Esta manera de combatir, que pudiera llamarse 'guerra de posiciones' o tener cualquier otro nombre, se caracterizará por un grande e intensivo apegamiento al terreno y sus principales elementos de acción, serán: la pala, la dinamita, el cañón de un calibre cada día creciente y el fusil con velocidades iniciales considerablemente superiores a la nuestra actual, capaces de producir trayectorias totalmente rasantes dentro del límite visual de tiro del infante." (RM, febrero de 1915, 253).
} 
duración, y luego el de su aspecto enteramente novedoso: su carácter industrial. Combustibles, gases y otras sustancias químicas, tanques, aeroplanos, trenes, electricidad, armas a repetición, armas cortas, armas de precisión, de largo alcance, globos aerostáticos, aviones de logística y aprovisionamiento, pero también la situación de la caballería frente a un "colchón de fuego" o el problema del enlace entre infantería y artillería en el marco de una guerra con un "vacío del campo de batalla".

Un nuevo dominio de artefactos, saberes y roles, sin mencionar la puesta en discusión de la organización básica de los ejércitos, de las estrategias y tácticas de las batallas, se abría así a la reflexión y al conocimiento. Y el primer efecto de todo esto fue el borramiento de las antiguas diferencias en cuanto a los fundamentos de la organización militar de excepción de los ejércitos sudamericanos. El criterio de corte y diferenciación a uno y otro lado del atlántico ya no se buscará en la concordancia con la idiosincrasia de cada pueblo, la tradición de los vínculos locales del ejército con la población o el perfil de las legislaciones y el espíritu de sus leyes, tal como había sucedido hasta comienzos del siglo. Las "enseñanzas de guerra" atentaron de modo efectivo contra los últimos resabios de aquella visión de una idílica comunidad armada en función de sus propios temperamentos y modo de organización histórica. De aquí en adelante el carácter técnico-económico de los conflictos horneará las percepciones y los juicios sobre las que construirán clasificaciones y tipologías, elogios o admoniciones, respecto al presente y futuro de los ejércitos y los estados que los organizan y preparan. Fue recién entonces cuando llegó a constituirse como una evidencia, la necesidad de un "aparato estatal" para la guerra. El segmento "Digesto de Informaciones militares", en el índice del número de diciembre de 1919 de la RM, creo que permite precisar aquello a lo que me refiero.
Ametralladora ligera Beradmore-Farquhar modelo 1919.- Automovilismo: Abuso de utilización de los automóviles militares.- Aviación: Desarrollo de las fuerzas aéreas durante la guerra.- La escuela militar de aviación de campo Hoare (Canadá).- Creación en Francia de una inspección técnica de la aeronáutica.- Convenio relativo a la navegación aérea internacional.Barnices para alas de aeroplanos.- Empleos de hélices lacadas.- Los transportes aéreos.- Escuelas. Estudio comparativo sobre las escuelas militares del Perú, Argentina, Brasil y Chile.Moral: El miedo al peligro entre los combatientes.- Industrias: Precauciones para la soldadura de las piezas de aluminio.- Líquidos más convenientes para niveles de aire.- Nuevo acero para herramientas.- Una aplicación del frío.- Nuevo procedimiento para preservar el hierro de la oxidación.- Farmacopea. Colusión Carrel.- Historia militar: la batalla de 1918. ("Sumario", s/p, diciembre de 1919 [el resaltado es original])

Se trata de una compilación de temas de órdenes diferentes - aunque en su mayoría técnico-industriales - en función de sus vínculos con la guerra. Es esta la que los ordena en su contigüidad y a la vez el foco de sus innovaciones y novedades. Esta serie de intereses y preocupaciones cristalizará en poco tiempo - al provocar por contraposición una profunda sensación de carencia - en algunas políticas públicas. La "Ley de armamentos" de 1923 fue a la vez un efecto de este clima y un estímulo importante en esta dirección. Resultaba un programa que si atendía a la compra de armamento en el corto plazo, aspiraba a apoyar la industrialización militar y civil en el país. De este modo, con fondos de este programa se llevaron adelante en 1926-1927 la construcción y puesta en funcionamiento de la Fábrica Militar de Aviones en Córdoba así como, en parte, la destilería de crudo en Mar del Plata en $1925^{11}$.

Sin embargo, lo que quisiera remarcar aquí es que para estos años comenzaba a gestarse

\footnotetext{
11 El escueto programa de adquisición de armamentos y pertrechos bélicos contemplaba explícitamente el "fomento de la industria metalúrgica, instalación de altos hornos, modernización de material de guerra existente y fábrica de pólvora”. En las Memorias del Ministerio de 1924, el general Justo vinculaba este proyecto con la posibilidad de "establecer en el país fábricas y talleres que nos sirvan de base para independizarnos de la industria extranjera, como lo imponen, tanto necesidades de índole militar, como razones de economía" (MMG 1924: vii). Con respecto al interés militar por la industria aeronáutica numerosos artículos (en muchos casos traducciones) de la RM durante y fundamentalmente con posterioridad a la guerra, así como otras publicaciones, dan cuenta de su persistencia y regularidad. Entre otros se pueden ver, "De la guerra actual. Aeroplanos", RM febrero de 1915: 270-273; "Aeroplanos de infantería", (RM enero de 1923, 146); "Depósito de gasolina para aeroplanos", (ídem, 154); "Nuevos acumuladores ligeros para aviación", (ídem, 158); "La fotografía desde el aeroplano", ídem: 167; "La guerra aérea", (ídem, 169); "Táctica aérea", (RM octubre de 1923, 1185-1192); "Notas sobre el empleo de la aviación en la infantería", (RM noviembre de 1923, 2063-2068); “Contribución al estudio de la organización y del reglamento táctico de aviación” (RM enero de 1920, 33-46);
} 
una suerte de "efecto de síntesis" en el pensamiento militar. Incorporando primero algunas traducciones aisladas respecto a la dimensión económica de la guerra, las descripciones de los adelantos en los artefactos técnicos serán incluidas de modo creciente en una visión más general, yuxtaponiendo lo tecnológico a lo económico primero, y esto a una organización estatal después ${ }^{12}$.

Lo que la literatura académica posterior ha señalado respecto al rol de la primera guerra en una suerte de proto-industrialización forzada de la Argentina (Caravaca, 2011, 74; Gerchunoff, 2016, Badoza y Belini, 2016), era uno de los elementos en la percepción de no pocos cuadros militares en esos años. A lo largo de las décadas del '20 y '30, las lecturas retrospectivas ubicarán al periodo 1914-1918 como una fase casi originaria para el proceso industrializador militar argentino.

La guerra 1914/1918 constituye para las instituciones armadas un acontecimiento cuyo estudio tiene una importancia tan trascendental que exige la atención más grande y la dedicación más afanosa de todos sus miembros directores... los ejércitos que se mantuvieron alejados de la contienda deben emprender reformas importantes en su organización, reglamentación y armamento. [...] Los progresos asombrosos de la indus- tria bélica han traído cambios fundamentales en el armamento, en los medios de comunicación, mejor dicho, en la técnica, etc.; y esto debe ser conocido primero con detalles por los interesados más directamente y luego en sus relaciones con la conducción de las tropas por los comandos de cierta categoría." (RM mayo de 1921, 613-614)

"Basta reflexionar sobre la forma cómo se desarrolla la guerra en la época actual para comprender la necesidad de organizar la defensa nacional del país... En una palabra, vincular poderosamente las industrias y el comercio con las instituciones armadas del país. Los que piensan que la preparación militar del país ha de ser realizada únicamente por los poderes públicos de la nación se equivocan grandemente... las cuestiones relativas a la defensa nacional interesan profundamente a la economía general del país. [...] Cada uno de los ministerios va por su lado e independientemente y cada uno considera con criterio distinto la forma de preparar el país para la guerra. ¿Se puede concebir una mayor anarquía? (Auditor de Guerra, 1923. Citado en Yelpo 1987, 26) ${ }^{13}$

No resulta fácil precisar la relevancia de este fenómeno. La entrada de un análisis económico en las reflexiones militares adquiere una potencia sensible al comprender que el

\footnotetext{
"Defensa contra ataques aéreos" (RM febrero de 1920, 263-273); "De un informe sobre aviación” (ídem, 273-279); "Raids aéreos sobre Londres" (RM julio de 1920, 1233-1236); "Fuerza aérea nacional chilena" (RM agosto de 1920, 1538); "Puntos de vistas personales para nuestra organización aeronáutica" (RM noviembre de 1920, 1635-1643); "Conferencia dada en la escuela militar de aviación a los señores oficiales alumnos" (RM febrero de 1921, 207-230); "Las hazañas militares de las aeronaves Zeppelin durante la guerra" (RM diciembre de 1921, 1485-1494); "Aviación militar" (RM enero de 1922, 11-32); "El avión proporciona a la artillería economía de munición" (RM marzo de 1922, 369-375); "La aviación en Alemania" (RM mayo de 1922, 589-592); "La preparación para la guerra aérea", (RM agosto de 1922, 99-906); "La aeronáutica en Francia durante la gran guerra" (RM julio de 1923, 51-68). La publicación Estudios y Comunicación de Informaciones (en adelante ECI) de la Escuela Superior de Guerra, le dedicó un dossier a la aviación francesa en su volumen XI de 1925.

En forma paralela, el mayor Crespo publicó en 1923 el libro El problema de la aeronáutica en el país (como factor económico y de defensa nacional). La singularidad de esta pieza está cifrada en el solapamiento explícito que allí se produce entre los problemas militar y económico, lo que también comenzaba a suceder con el combustible y el hierro. En el capítulo cuarto el autor lista las ventajas del desarrollo de la industria aérea, puntualizando los siguientes factores: (a) utilización de materias primas locales; (b) fomentando la aviación comercial, se impulsa una serie de proyectos industriales paralelos; (c) se facilitan los casos de movilización de contingentes; (d) mayor comunicación entre las distintas regiones del territorio (fundamental para la unificación cultural); (e) posibilidad de mayor intercambio con los países vecinos; (f) Provisión al mercado local y extranjero; (g) "Y por último, tengamos bien en cuenta que la aeronáutica da la oportunidad a los países pequeños que desarrollen la industria de alcanzar la victoria contra un enemigo cuya población y recursos sean mayores, porque las conveniencias de orden civil y las de orden militar son fácilmente conciliables." (Crespo 1923, 44).

12 Se puede ver "Las economías implantadas por el gobierno británico y la administración militar en los gastos de la guerra", (RM mayo de 1919, 542-574); "Los gastos de la guerra", (RM junio de 1919, 904-906); "Francia. Los empréstitos de guerra", (RM julio de 1919, 1164-1165); "Italia. Esfuerzo económico y financiero", (ídem: 1172); "La nacionalización de las industrias de guerra bajo el punto de vista artillero (con grabados)", (RM julio de 1919, 1177); "El problema del ejército descansa sobre la movilización de las fuerzas industriales" (RM julio de 1920, 1275-1278); "Índice económico de la República Argentina” (RM julio de 1921, 14211433); "Como se preparan, sostienen, liquidan y disfrazan las finanzas de guerra" (RM agosto de 1923, Anexo, 1-19); "La industria y la producción como factores de la riqueza pública y la defensa nacional" (RS, No 52 septiembre de 1923, 1-2), "Economía nacional. Su influencia en la conducción de la guerra. La guerra de las naciones en armas (RM, septiembre de 1927).
}

13 Percepciones similares pueden verse en la compilación de Antonio Yelpo (ob. cit.), como las de los mayores Franklin Reyes en 1934 (p. 43) y Carlos Martínez al año siguiente (p. 55) y el teniente coronel Sanguinetti en 1943 (p. 117). 
vértice que representa este cambio de época, encuentra al progreso militar y al progreso económico como dos procesos que caminan juntos. Ahora bien, si en los años inmediatamente posteriores a la guerra, la lectura predominante anclaba en un necesario desarrollo militar apoyado en un no menos necesario acompañamiento económico-estatal, rápidamente las consideraciones se extendieron hasta precisar los beneficios para la población y la economía en general de un proceso industrializador. Los mojones que permitían cubrir la distancia entre ambas zonas - el desarrollo particularmente militar y la orientación económica general que debía seguir el Estadoeran las figuras retóricas de independencia, fortaleza y soberanía. Debido a ello, más allá de lo discutible que pudiera parecer frente al desfile de indicadores económicos aquella identificación del periodo bélico con un proceso industrializador, lo que difícilmente podría desecharse es lo inaugural de este tipo de reflexión en el pensamiento militar. Me refiero concretamente al interés por $-\mathrm{y}$ la capacidad de - segmentar un periodo en el que algo "nuevo" sucede, y a la vez intentar definir las condiciones de perdurabilidad de aquello que emergió de manera contingente.

Durante los cuatro años de guerra, nuestra industria mecánica se ha desarrollado en un porcentaje bastante elevado, pudiendo fabricar máquinas y otros elementos para las necesidades del país y en muchos casos ha exportado sus productos a los Estados europeos, pero terminada la gran conflagración, se ha notado que únicamente ha seguido experimentando su crecimiento la industria metalúrgica de la construcción, debido a la creciente edificación en nuestra república, mientras que la industria de la mecánica en general ha sufrido una notable disminución por el hecho de haber sido reducidos y eliminados los derechos de importación de las máquinas en general, sin tener en cuenta, por lo menos, de proteger las que se fabrican en el país en grandes cantidades, en iguales o me- jores condiciones que sus similares extranjeras. (RM 1926, 737)

Este principio de cálculo que parte por identificar la fortaleza de los estados con su desarrollo industrial, y que en base a ello detecta una debilidad fundamental en la estructura económica local, resultaba compartido por las diferentes intervenciones sobre el tema alrededor de la mitad de la década del '20, entre ellas dos piezas muy celebradas por esos años y que de modo más decidido avanzaban en la producción de juicios y prescripciones sobre la conducta económica del Estado (ya desenganchada - directamente al menos - de la organización militar). El estudio del coronel Vicat, el más reconocido por sus contemporáneos y citado por los trabajos recientes de Forte y Daiçková, había sido en realidad una conferencia desarrollada en el Círculo Militar en julio de 1925, y que parece haber llevado el título "Defensa Nacional Industrial: bastarnos a nosotros mismos"14. Dos de las líneas de fuerza de esta pieza, el juicio de que la dinámica productiva del país resultaba del todo conveniente a las naciones industriales, y que la organización del comercio internacional admitía dos proyectos contrapuestos, una vinculación armónica aunque desigual de países industriales con agroexportadores o una disputa por intereses enfrentados, no dejaba mucho margen de acción en materia de conducta estatal ${ }^{15}$. De todas maneras, el interés de Vicat seguía muy cercano a los desarrollos tecno-económicos específicamente militares. No ocurre lo mismo con el trabajo del mayor Barrera, centrado límpidamente en una discusión sobre el desarrollo económico general.

Estamos realmente en lo que yo llamaría la época del combustible, ya que las potencias mundiales luchan para obtener las mayores extensiones de territorios ricos en combustibles y hierro porque saben que sin ellos la grandeza, progreso y desarrollo del bienestar humanos no pueden realizarse sobre bases sólidas y duraderas.

14 Su difusión por fuera de los círculos militares fue casi inmediata. A dos años de su presentación en el Círculo Militar el ex gobernador de Salta Benjamín Villafañe, publicaba "La miseria de un país rico", una compilación de escritos propios y de referentes públicos en el país, y en la que la incluía como uno de sus capítulos. Se la volvió a publicar en 1964, junto a otros escritos militares bajo el título "Ejército y Revolución Industrial".

15 En un tono similar, el capitán Marambio definía en 1936 la situación creada por la primera guerra "[A]l contemplar desde allá [Europa] los otros continentes, se vio con estupor que la guerra había industrializado a muchos países extraeuropeos; que estos trataban de independizarse de sus antiguos proveedores y que, en definitiva, la conquista de los mercados, tal como se supuso al principio, no iba a resultar tarea sencilla... La evolución operada ha ido más allá de lo sospechado; Europa no constituye ya el único e indiscutido centro de las actividades industriales." (citado en Yelpo, ob. cit., 59). 
Nosotros, argentinos, pastores, propietarios de inmensos ganados y pastizales adecuados para la alimentación de los mismos, descuidamos nuestro porvenir porque no encaramos el verdadero problema que dará la grandeza a nuestra tierra: la explotación intensiva y científica del petróleo, del carbón y del hierro, que nuestro subsuelo nos guarda como una reserva para nuestra prosperidad. [...]

Teniendo combustible y hierro... seremos libres, tal como los países más grandes, porque la libertad no existe cuando no va acompañada de la independencia económica. (RM octubre de 1923, 466-467)

Como puede percibirse, el centro de los intereses es la conducta de los estados mayormente desarrollados, con una discusión velada además sobre el sistema de relaciones económicas interestatales. Sobre este punto, en ambas intervenciones la viabilidad de una posición del país en el mercado internacional apoyado en su identidad agroexportadora, resultaba fuertemente cuestionada.

La inquietud por la organización militar en ningún momento dejó de estar en el frente de las propuestas. Lo que resulta necesario comprender es que, como ya lo señalé más arriba, el pensamiento militar dispone por estos años de mojones temáticos y retóricos con los que pasar del desarrollo militar-industrial al desarrollo económico general y viceversa. Esos pasajes retóricos cristalizarán en una fórmula precisa a finales de esa década, que aparecerá en primer lugar como un curso extracurricular en el Colegio Militar y será más tarde un curso regular en la Escuela Superior Técnica, dictado por su director el general Savio. Se trata de la "Organización Industrial" y en ello me detengo en el siguiente apartado.

Todo lo anterior no puede llevar en ningún caso a identificar algún tipo de interven- ción militar en la vida económica. Más aún, a excepción del proceso ligado a la producción local de combustible y el surgimiento de la empresa estatal Yacimientos Petrolíferos Fiscales (Y.P.F.), resulta necesario relativizar fuertemente el peso de los grupos militares en la organización de la economía interna del país y de su política exterior en los años '20. Lo que he tratado de visibilizar en estas páginas no es más (ni menos) que la emergencia de juicios y reflexiones militares que reclaman una orientación particular de la conducta económica del Estado.

\section{El acero, el combustible y su organización}

Intencionalmente he obviado en el apartado anterior todo señalamiento y análisis de las reflexiones y juicios de los dos íconos del proceso de proyección militar-industrial del periodo: Enrique Mosconi y Domingo Savio. He querido con ello visibilizar en primer lugar el trasfondo desde el cual los proyectos de estos dos militares pueden comprenderse. Lejos de representar casos sui generis o fenómenos de outsiders, considero se trata de las exposiciones más logradas del mismo ethos militar de gobierno que este estudio trata de hacer visible. En ambos casos se sostienen como mutuamente apoyados la potencia bélica militar y un desarrollo económico nacional y también en ambos casos se asumen de manera decidida prescripciones orientativas para la conducta económica del Estado.

A diferencia de Savio, en el caso de Mosconi puede verse con nitidez la progresiva incorporación de temáticas económicas en el rumbo de sus reflexiones ${ }^{16}$. No existen prácticamente menciones a la autonomía armamentística previo a los años en que fuera Director del Arsenal "Esteban de Luca", y sus elucubraciones sobre

16 El general Mosconi publicó en sus últimos años dos trabajos que, si bien similares, tienen una importancia diferente para este estudio. El petróleo argentino, 1922-1930, es en buena medida una narración a posteriori de su desempeño como director de Y.P.F y de las vicisitudes de las políticas desplegadas. El prólogo de la segunda edición de 1958 daba cuenta de la pobre recepción que su aparición había tenido en esos veinte años. Tuvo una tercera y última edición en 1983. Dichos y Hechos 1904-1938, es su segunda y última publicación, y resulta una compilación de discursos, conferencias y artículos que van desde la construcción de cuarteles hasta la política petrolera que deben seguir los países de Latinoamérica, pasando por la planificación de rutas aéreas nacionales, entre otros asuntos. En general, me detendré en esta última pieza, pues contiene material cuya temporalidad no supone - como en el caso de El Petróleo Argentino - un ejercicio intelectual de reordenamiento post facto de los hechos (ello no conlleva, en ningún caso, alguna consideración de mi parte respecto a algún tipo de diferencia en los juicios y modos de reflexión sobre el petróleo o la economía). De modo posterior a su muerte y en lo fundamental en la segunda mitad del siglo pasado, numerosos estudios han recuperado, ya sea de forma directa o como parte central de la historia del petróleo en la Argentina, la vida y el pensamiento de Mosconi. Rescato particularmente la compilación hecha por Gregorio Selser en 1956 La batalla del petróleo: YPF y las empresas extranjeras, así como los tres tomos de escritos y discursos compilados por Gregorio Weimberg y Raúl Larra en 1958, El Petróleo Argentino, YPF contra la Standard Oil y La nacionalización del petróleo. 
"el petróleo y la cuestión nacional" emergen de manera posterior a su designación en Y.P.F. Una vinculación directa de los intereses político-civiles con los de tipo militar comienza a fraguarse en sus años de Director del servicio aeronáutico del Ejército, y llega a tener para finales de la tercera década un carácter casi prescriptivo ${ }^{17}$.

En cada una de estas etapas, las reflexiones de Mosconi siguen un derrotero similar al que describí en el anterior apartado. En primer lugar, una plena conciencia de la necesidad de un autoabastecimiento de material de guerra, seguido a esto el interés por una conducta estatal que lo estimule y sostenga, terminando por argumentar a favor de la economía estatal tout court, una vez paralelizados los intereses civiles y militares. De hecho, con el correr de los años Mosconi parece haber ido fraguando y complejizando una idea de la independencia del país, a la vez etapista y evolutiva. Si en 1918, interesado en robustecer los pertrechos militares, afirmaba que "[1]a independencia del año 10 debe ser integrada con la independencia de nuestros cañones" (Mosconi 1939 [1918], 34), diez años más tarde esa percepción tomaba una nueva forma. "Nuestros países inician el tercer período de su evolución: a la emancipación sucede la constitución política y a esta debe suceder la organización económica" (Mosconi 1939 [1928], 171). En este contexto la cuestión del petróleo le permitió ir más allá de estas prescripciones generales y de los diagnósticos y pergeñar modelos organizativos de funcionamiento de aquella leyenda relativamente común aunque aún amorfa en el mundo militar de mediados del '20: el nacionalismo económico.

El monopolio al que se refería Mosconi, significaba concretamente que los "criaderos, fuentes y depósitos naturales de petróleo, así como los hidrocarburos gaseosos que se encuentran en el subsuelo y que escapen de la superficie de la tierra" debían ser declarados "bienes privados de la Nación". Esto excluía tanto la posibilidad de la concesión de licencias a firmas internacionales o nacionales, pero también el usufructo por parte de los gobiernos provinciales de tales recursos, ante una posible "anarquía de interpretaciones de 15 poderes".
Sin embargo, la estructura comercial montada sobre esta exclusividad era mixta - solventada con capital estatal y privado de preferencia nacional, aunque sin excluir taxativamente la participación de firmas extranjeras-. Mosconi no era partidario de un monopolio estatal de la producción y comercialización de combustible, ya que estimaba a esta figura como "propiciadora de falta de competencia, frondosidad administrativa, pesadez burocrática, falta de iniciativa y encarecimiento de la producción". Si a todo esto se suma el caso de que "el comité político llega a ejercer influencia sobre la marcha de la organización", el resultado es una "calamidad"18. Mosconi acordaba prioridad al Estado nacional para sostener, llegado el caso, una política petrolera de excepción (ante un estado de guerra, por ejemplo) y a la vez propiciaba una desvinculación necesaria del gobierno del Estado respecto del petróleo en tiempo de paz.

De modo que el Estado asumía un doble papel. Si excepcionalmente podría llegar a ser un jugador exterior al mercado, en tiempos normales jugaría según sus reglas.

Las prescripciones del código de comercio regularían el funcionamiento de la organización y el Poder Ejecutivo delegaría en los representantes del capital privado la dirección de las funciones técnicas y administrativas; pero reservando para el presidente y los dos directores que lo representen el derecho del veto a las resoluciones del directorio que importen modificación de estatutos, habilitación o adquisición de nuevos yacimientos y disposiciones que tengan conexiones internacionales y con la política de precios. [...]

... con el fin de que el capital privado se sienta estimulado para la constitución de esta sociedad, se deja el riesgo de las explotaciones al Estado, que las realizará con la parte de beneficios que corresponde al $\% 51$ de sus acciones y sólo después de haber efectuado descubrimientos y determinado el valor económico de una zona la entregaría a la organización mixta, que tendrá a su cargo la organización de la producción, transportes, elaboración, distribución y venta. (Mosconi ídem, 168)

17 " $[E] n$ nuestros días, en que el comando superior debe conducir al pueblo en armas, los jefes del Ejército no pueden permanecer ajenos al conocimiento del desarrollo económico de la nación. Más aún: dentro de los posible, debemos adquirir la mayor aptitud para conocer dicho factor que integra el poder del Estado, estimular su desarrollo y cuidar su progreso, dentro del más sano y completo nacionalismo." (Mosconi 1939 [1929], 198).

18 Esta línea argumental en Mosconi 1939 [1928], 164-166. 
La decisión de agosto de 1929 de bajar el precio de venta de los productos de Y.P.F, si era una intervención estatal en la economía sustentada en criterios extraeconómicos una mayor federalización del consumo y no la obtención de mayores réditos-, no es menos cierto que su modalidad resultaba compatible con herramientas del propio mercado. Al igual que otras elucubraciones sobre la organización económica por parte de los cuadros militares, la de Mosconi buscaba la forma de congeniar la presencia del Estado en la dirección de algunos asuntos económicos con el aporte de capitales no estatales.

El nacionalismo económico del ethos militar en esa tercera década no es en ningún aspecto incompatible con el capital privado nacional e incluso algunos capitales extranjeros. Antes que "estatista", Mosconi particularmente asume un discurso de "empresario estatal" o "empresario público". Descree de la formación espontánea del precio en mercados con fuerte asimetría en el nivel de inversión y capacidad productiva, y asume un diagnóstico dicotómico. En tales mercados, el precio lo ponen los trust o los pone el Estado. Por un interés "superior" o "nacional", pero no político, es preferible lo segundo. Con mayor razón en los productos ya entonces considerados "estratégicos" como el petróleo. Sin embargo, que ello suceda no es obstáculo para la obtención de ganancias por parte de particulares y sencillamente para él, esto no era un asunto del Estado.

El fuerte acento latinoamericanista de sus posiciones en el marco de sus visitas a México, Colombia, Perú y Chile en 1928 estaba directamente vinculado al objetivo de prevenir a esos países de la conveniencia de una regulación similar a la encarada en Argentina, sobre el mercado de combustibles. Su tono vanguardista evangelizador atacaba directamente a dos o tres firmas hegemónicas e incluso a algunos sectores políticos de Estados Unidos, pero no incluía ningún apotegma respecto a los capitales privados en tanto tales, más allá del recaudo necesario que los estados deben tomar para orientar sus políticas petroleras. Y esto parecía ser uno de los topes en el pensamiento de Mosconi. Mantener un mercado de combustible que sea un factor de desarrollo de la potencia industrial del país, basado en la propiedad estatal de los pozos, la organización mixta con riesgo inicial del Estado, e intervenciones regulatorias con instrumentos clásicos. No se encontrará entre sus preocupaciones o anhelos más apremiantes, esquemas o prescripciones para el resto de la organización productiva del país, más allá de la cuestión de los combustibles.

Fue Savio quien avanzó en profundidad en un diagrama industrial general, anudando con mayor fuerza ya no tanto la idea de soberanía, sino de "fortaleza económica" a figuras arquitectónicas institucionales y territoriales más precisas. Savio llevó a otro nivel las expectativas de los cuadros militares de organización industrial del país, y si bien la cuestión de los capitales capaces de posibilitar los emprendimientos industriales no fue un punto atendido, no puede restarse valor a su contribución en colocar al ejército como un lugar de enunciación relevante de las políticas económicas.

La apertura de la Escuela Superior Técnica (EST) en noviembre de 1930 tenía por objetivo, de acuerdo a un hagiógrafo del general "preparar y disponer de recursos humanos militares altamente calificados para llevar a cabo un programa de industrialización" (Domínguez, 2012: 27). Por otra parte, Robert Potash identificó a la EST como una suerte de think tank "promotora de las doctrinas económicas nacionalistas en el seno del ejército" (Potash, 1971: 118) ${ }^{19}$.

La EST había sido creada como un desprendimiento de un "Curso Superior y Especial" para los egresados del Colegio Militar. El curso que estaba a cargo de Savio se denominaba "Organización Industrial", y contenía dos líneas de formación. Por un lado, se profundizaba en aspectos relativos a la organización del trabajo, para lo que Savio había traducido "Organización del trabajo", del capitán Dumez — profesor de la Escuela Superior Técnica de Artillería de Francia - y algunos pasajes de "Organización metódica del trabajo", del mayor Denis - profesor de la Escuela Superior de Aeronáutica y de construcción mecánica, también de Francia-. Savio comprendía que esto tenía una importancia capital en la capacidad productiva, tanto de las actividades del ejército como en la organización general de la

19 En lo que sigue, me concentro en la EST y en el periodo temprano de acción de Savio, ya que resultan contemporáneos a los últimos años de despliegue de Mosconi y también están en los límites de la periodización de este estudio. 
vida económica. A su vez, sus lecturas claramente excedían las fuentes militares y es seguro concluir que estaba en conocimiento de los referentes internacionales en la materia ${ }^{20}$.

El segundo aspecto de atención en el curso de Savio estaba vinculado a la arquitectura institucional, territorial y social que supondría un despliegue industrial general de excepción, para el caso de guerra. Sobre este aspecto, el mismo Savio dio forma escrita a sus clases de 1933 en el curso "Movilización Industrial" que terminó siendo un manuscrito de unas casi doscientas páginas publicado con carácter reservado en septiembre de ese año ${ }^{21}$.

De un modo mucho más explícito que en cualquier otro caso, en Savio el problema de la industrialización del país consistía en un asunto derivado del carácter de las guerras modernas. Unos cuantos años antes de la creación de la Dirección General de Fabricaciones Militares (DGFM), o de la Sociedad Mixta Siderúrgica Argentina (SOMISA), ya había diagramado - de manera extremadamente detallada sus esperanzas y anhelos en relación al tipo de organización económica que consideraba óptima y esperaba posible, ante la eventualidad de una situación de guerra- La estructura del manuscrito de aquel curso de 1933 permite apreciar lo solapado que estaban los asuntos económicos y militares.

La preocupación central del curso era, más que la organización económica, su adecuación a un hipotético tiempo signado por las operaciones militares. Todo el curso era una propuesta compleja de organización y funcionamiento de la economía en tiempos de excepción. Bajo el trasfondo de comisiones y subcomisiones técnicas, regiones industriales y estadísticas, Savio se esforzaba en identificar los requerimientos económicos de la guerra. Todo esto es diferente a la demanda histórica de los cuadros militares respecto a la modernización del ejército (ampliación del presupuesto $\mathrm{y}$ cumplimiento de lo pautado al respecto). Aquí se trata en principio de una necesidad de conocer en detalle la potencia productiva del país y de especificar la ventaja que esto comporta a una organización militar. Esta diferencia era a la vez un efecto del cambio en el punto de vista respecto a lo que constituye justamente una "potencia militar".

La importancia material de las fuerzas armadas depende del potencial del país.

Si se pensase armar un ejército excesivamente numeroso y lo mismo una Marina demasiado importante, se tendrían en el primer momento organismos de choque poderosos capaces de afectar seriamente la acción enemiga, pero si ellos no pudiesen decidir la guerra en los primeros meses se convertirían rápidamente en conjuntos pesados, débiles y difíciles de conservar. $[\ldots]$

Nuestra tesis no es menoscabar el valor que representa contar de primera intención con un Ejército numeroso y fuerte. Lo que deseamos evitar es que se le asigne el carácter de fuerza decisiva $y$, por otra parte que no se exageren sus proporciones en forma de que constituye un cuerpo demasiado voluminoso y de débil constitución. (Savio ídem, 41.)

El modo de comprensión por parte de Savio, situado en el mismo lugar que buena parte de las reflexiones militares de esos años sobre la economía, y con La Nación y sus armas, del coronel de Estado Mayor Crespo (1938), como una pieza a la vez oculta y emblemática, representa una fórmula que hace sopesar el carácter exclusivamente militar de la defensa nacional (hombres y artefactos) con la solvencia material del Estado y la sociedad civil para sostenerlo en el tiempo, en caso de entrar en combate. El coronel Justo lo había anunciado una década atrás, "ya no se juega en los campos de batalla la existencia de un ejército". Aquí se trata del tipo de ejército que una organización social y económica puede mantener.

20 "[C]onsideramos que en las cuestiones de preparación de la Defensa Nacional, conviene aplicar los mismos principios de Taylor para la organización administrativa de las fábricas como expresiones vivas de actividades complejas, en los cuales preconiza una subdivisión especializada del trabajo y una dirección competente que armonice el conjunto dentro de la finalidad perseguida, que en este caso es el bien de la Patria." (Savio 1972 [1933], 40-41).

21 Este material fue editado públicamente, junto a otros trabajos de Savio, en 1972 (edición de consulta). La noción de "movilización industrial" tenía cierta circulación en los oficiales por esos años. Ver "La movilización industrial en lo referente a la fabricación de armas y munición de guerra. Sus principales problemas" (RM febrero de 1933, 201-228); "Movilización industrial, su necesidad. La experiencia de la guerra", (RM diciembre de 1934, 1235-1267). En los casos en los que era mencionado, este nuevo asunto de reflexión remitía a las experiencias de Francia y Alemania en la gran guerra (aunque las escasas fuentes citadas corresponden más a la primera). Por su parte, la propia literatura sobre este concepto recorta estos años cruciales como el periodo de su nacimiento (Ver Porte 2005, 2006; Balderston, 2010). También y bajo el título de “Movilización Industrial”, Savio desplegó un ciclo de nueve conferencias en el segundo semestre de 1934 que se dictaron en las instalaciones del Círculo Militar. 
Por ello es que tal vez sea esta una de las piezas más claras y potentes que permiten comprender la manera en que, en la década de 1920 y principios de los treinta, la situación económica del país entraba en las reflexiones militares. Pero permite comprender a su vez que la "Movilización" es un hecho enteramente dependiente de la organización de la vida en tiempos normales y no excepcionales de la guerra. De hecho, el problema de la "Movilización industrial" rápidamente dio paso en Savio al del "desarrollo industrial" o la "fortaleza industrial", en el que se sustentó su principio de hacer del Ejército un actor importante en la organización industrial del país, cuestión compartida por no pocos cuadros militares por esos años y que tendría efectos en la orientación económica del Estado en los años posteriores $^{22}$. De ese modo, aquella preocupación de la década de 1920, relativa al diagrama general de coordinación de lo económico y lo militar, derivó - no sin estímulos provenientes de otros actores sociales y económicos- en propuestas de reconversión y modernización de la infraestructura industrial del país en la década de 1940. Nada de esto último es asunto de este estudio, dedicado particularmente en estas páginas a visibilizar el modo en que los problemas económicos - ciertos aspectos de la conducta económica del Estado - pasaron a formar parte del paisaje de juicios y reflexiones de los cuadros militares, constituyendo uno de los rasgos de la racionalidad militar.

No son pocos los matices que diferenciaron las inquietudes y preocupaciones de Savio y Mosconi. Y no me refiero a sus zonas particulares de interés, el acero y el combustible. Si en un caso, la fortaleza militar residía en la soberanía económica, en el otro residía en la capacidad organizativa del Estado. Por otra parte, mientras Mosconi parece particularmente interesado en la organización vertical de un sector productivo - en el caso del petróleo, desde el estudio geológico de los suelos hasta la destilación, transporte y venta del producto-, en Savio se observa un interés por la organización coordinada-horizontal de los distintos sectores — de allí la percepción de una mirada más panorámica en este caso-.
Mucho mayor aún es la diferencia ideológica. En la mañana del 6 de septiembre de 1930, Mosconi había corrido al Arsenal de Guerra para organizar la resistencia al golpe de estado liderado por el general Uriburu. Savio, por su parte, ocupó un cargo de relevancia en la organización de ese movimiento. Aquél fue encarcelado primero, enviado al exterior después, $\mathrm{y}$ simbólicamente proscripto al final, haciendo coincidir sus últimos años con un ostracismo interno, un aneurisma y el cuidado de las hermanas. Este comenzaba sus quince años de mayor incidencia en el ejército y a la vez de notoriedad pública.

$\mathrm{Y}$ a pesar de todo, comparten un mismo modo de problematización respecto de la serie Ejército-Estado-Economía. En ambos la primera guerra y la concomitante reorganización de las relaciones interestatales resultaron factores cruciales para la elaboración de juicios y proyectos, diagnósticos y asesorías. En ambos se encontraba presente la percepción de un tiempo en el que el ejército - en el cuidado de su propia salud y fortaleza- debía decir algo respecto a la conducta económica del Estado y derivado de esto, la convicción de que el Estado podía intervenir a partir de "planificaciones" en el rumbo económico. Además, la tendencia a asignar al sector industrial una prioridad sobre la agricultura o el comercio, a la vez que los ubicaba en otro cuadrante que las elites económicas de su tiempo y que permitía ver su orientación por una "economía organizada", no suponía en ninguno de los dos casos una defensa sin restricciones de la estatización de la vida económica, en detrimento de los capitales privados.

Pero no pueden comprenderse por sí mismos. No son las figuras individuales de Savio y Mosconi, más allá de sus rasgos de personalidad y de los efectos de sus decisiones debido a los cargos que ocuparon, la sustancia relevante en este estudio. Fueron parte de un foco de problematización que recorrió libros y revistas militares desde comienzos de la década de 1920 y en los que las figuras de Justo, Barrera, Vicat, Baldrich, Rottjer, Crespo y otros jefes militares, contribuyeron a dar forma y carta de ciudadanía, pues de allí en más la relación

22 En 1945, al cumplirse el cuarto aniversario de la Dirección General de Fabricaciones Militares, Savio veía cumplidas parte de sus expectativas. "[L]e ha correspondido aquí al Ejército, otra vez más, participar efectivamente en el jalonamiento de nuestro progreso. Así como hace muchos años se adentró en el desierto para delinear ciudades y trazar caminos, hoy abre una puerta grande a la industrialización que al parecer está demandando desde algún tiempo un puesto más destacado en nuestras actividades." (Savio, citado en Echagüe, 1999, 66). 
entre ejército, economía y Estado, no dejó de ser considerada como un asunto del cual había justificadas razones para hablar puertas adentro de las escuelas militares, las comandancias y los casinos, pero también para esbozar en proyectos y programas de gobierno.

\section{Economía y conducta estatal}

A fin de cuentas, no es más que una idea sencilla. Una de las formas en las que el Estado fue objeto de reflexiones desde comienzos de la tercera década del siglo XX en adelante por los cuadros militares, está vinculada con su comportamiento económico, y estas provienen del fenómeno capital de la Gran Guerra, de su carácter industrial y del espesor de los vínculos entre los Estados. El interés militar por la conducta económica del estado tiene este nacimiento y en última instancia remite a la propia vida del ejército. En esta genealogía de sus reflexiones, lo que hay en el pensamiento militar es, en primer lugar, un cuidado de sí mismo. Un teniente alguna vez lo expresó en la RM, "para una nación la industria mecánica debería considerarse como la 'Industria de la Defensa"' (RM 1926, 737), y un estudio ya citado de ECI, admitía con amargura que, a casi una década de la finalización de las contiendas, seguía creyéndose que "la preparación de un país para la guerra, no comprende sino la preparación de las fuerzas armadas".

Si bien y por compartidas que hayan sido estas percepciones, no parecen haberse desplegado más allá del mundo específicamente militar, no debiera perderse de vista su singularidad, pues representan un gesto inaugural en varias direcciones. En primer lugar, significa un posicionamiento respecto al rol que el país había asumido en la organización económica internacional. Esto es un punto ya notado por Forte y Daickova, y de una manera un tanto más elíptica por Rouquié y Potash. No pocos militares habían enjuiciado críticamente la orientación agroexportadora del país, e incluso denunciado a los frigoríficos como el momento non plus ultra de industrialización bajo esa tendencia. No parece casual por otra parte que en la década de treinta, algunos empresarios industriales se hayan acercado a Savio para solicitar su colaboración en la arquitectura de un proyecto de fomento industrial. Incluso la misma posición latinomericanista de Mosconi representa en sí misma una novedad, que difícilmente haya sido bien asimilada por las elites locales ${ }^{23}$.

También pasó a ser cuestionada una modalidad específica del funcionamiento económico, cuya identificación estaba por lo general a cargo de los discursos de las izquierdas pero que comenzó a tener algún tipo de recepción en el mundo militar: los monopolios económicos. Sobre este punto Mosconi y Baldrich fueron dos de los principales instigadores, aunque bajo la crítica a los capitales extranjeros podrían señalarse posiciones cercanas en otros jefes militares. Sin embargo, a diferencia de las izquierdas, lo medular de la crítica pasaba por una concepción de la soberanía o la fortaleza estatal que no tenía relación con la condición de los trabajadores o el mundo del trabajo. La falla que introducen los monopolios en la vida económica no se encuentra en su carácter de "máquina de explotación" del ser humano o en ser una de las avenidas principales y de mayor efectividad de extracción de recursos hacia los centros nodales en la compleja urbanización del sistema económico internacional, sino en que resultan un actor de peso en el juego de poderes interestatales, particularmente aquél que queda descarnadamente al descubierto luego de la guerra. Las reflexiones militares no parecen asignar mayores créditos a una lectura que hace de la economía un sistema autorregulado con tendencia al equilibrio o uno que, no menos guiado exclusivamente por intereses económicos, siguiera la tendencia opuesta, la del desequilibrio absoluto. Con excepción del "materialismo apátrida y ácrata" con que en la década del '20 identificaban casi por igual a socialistas, anarcosindicalistas, comunistas y minoritariamente a judíos, los intereses económicos no resultan definitorios en la racionalidad militar. Por el contrario, detrás de las firmas económicas, la racionalidad militar tendía a ver Estados operando, que se valían de empresas y acuerdos económicos para fortalecer intereses extra económicos, nacional-estatales. No es extrema en ese sentido la visión que hace

23 "Las naciones de América tienen un evidente interés en prestarse mutua cooperación... Llegaremos a formar así un conjunto étnico, político, social y económico que se contraponga a la influencia impulsiva de la América del Norte y equilibre la acción, hasta hoy preponderante, de la influencia europea" (Mosconi [1929], citado en Yelpo ob. cit., 32). 
de la economía, en las reflexiones militares de esa tercera década, la continuación matizada de la guerra por otros medios.

Para finalizar este apartado, deseo consignar algunas indicaciones de periodización de esta relación a este modo de reflexión. Riccardo Forte entiende que la circulación de juicios sobre el Estado y la economía en el mundo militar está relacionada con "una crisis profunda y de largo plazo de la forma estatal liberal, que se veía cuestionada al comienzo de los años veinte desde distintas perspectivas ideológicas y por distintos sectores de la sociedad." (Forte 2003, 4). Por su parte, Rouquié parece identificar la emergencia de un pensamiento industrializador en el ejército en el último lustro previo a la segunda guerra (Rouquié ob. cit., 276-277). Aquí traté de señalar el modo en que, ya desde los años inmediatos de la primera posguerra comienza a tomar forma un tipo de problematización de la economía que resulta algo novedoso en comparación a lo anterior, no solamente porque ello (la pregunta específica por la conducta económica del Estado) no resulta regular ni pertinente a militares como Capdevila, Ricchieri, Godoy o Garmendia, sino porque no existía el marco de visión general que otorgaba la idea de "Defensa Nacional" tal cual había comenzado a ser formulada en los años de guerra y sobre la que se apoyaron las reflexiones sobre la economía.

Dos aclaraciones finales. Una de las preguntas que sin dudas puede hacerse el lector de estas páginas es respecto a la eficacia de toda esta fatiga intelectual. En este aspecto no me queda más que solicitar nuevamente cautela en la lectura. Me refiero a no sociologizar, es decir, no dar por sentado una presencia importante de los esquemas organizativos de la economía fraguados en el pensamiento militar, en las políticas públicas desplegadas, ni aún en la dictadura de Uriburu ni en la cercenada democracia de Justo. Más aún cuando tampoco en el mundo militar de la década del '20 la situación era muy halagüeña. Si los registros de conscripción permiten ver un adelanto importante en materia de cantidad de conscriptos anuales y de estabilidad de las redes sociotécnicas capaces de sostenerlo, la situación de armamentos e instrucción estaba, a pesar de los avances que en otros años hubieran parecido imposibles, tan o más desfasada comparativamente que antes en relación a las potencias militares, pues ahora debían realizarse las comparaciones con la era de posguerra, en la que los desarrollos tecnológicos tenían un peso mayor ${ }^{24}$. En todo caso, debiera buscarse la eficacia en otro lugar. Concretamente, en la emergencia y estabilización de la pregunta por la conducta económica del Estado en el pensamiento militar.

Un segundo interrogante que puede hacerse el lector remite a la homogeneidad del modo de problematización, teniendo en cuenta que no he presentado un rastreo de discusiones o posiciones encontradas al interior del mundo militar. ¿Existía realmente un consenso sobre esto? ¿Todos pensaban lo mismo? Resulta que aún quienes no apuestan a un futuro industrial del país - cuyo registro es realmente difícil de consignar-, reconocen el problema que este diagnóstico produce en el futuro del ejército. $Y$ este es el punto. No existía manera de escapar a esta forma de organizar reflexivamente el presente, del mismo modo que a finales del siglo XIX, cualquier discurso clínico y propositivo de la situación militar, debía afrontar como uno de sus primeros desafíos la relación pertinente y posible con la población masculina adulta, a los fines de su instrucción. Esto, lo que aparece como lo no pensable - en este caso, la posibilidad de existencia de una potencia militar vinculada a un Estado con orientación agroexportadora- $-\mathrm{y}$ no el consenso sobre las respuestas y las soluciones, es lo que define el límite de este modo histórico de problematización militar.

A diferencia de las corrientes de pensamiento económico de la época, la circulación de ideas y la institucionalización de un saber económico experto en la Argentina, los cuadros militares habían producido sobre un fondo de diagnósticos de la primera guerra, la yuxtaposición de los problemas de la defensa

24 Savio advertía en 1933 "[A]nalizando nuestra situación interna y la tendencia de ciertas opiniones políticas (salvo un cambio de ideas diametralmente opuestas), parece difícil que se consiga dotar normalmente a nuestras fuerzas armadas de todos los materiales indicados, para alcanzar en plazo breve el pie de guerra. [...]Un ejército cuyos oficiales de artillería no disparen doscientos tiros por año cada uno, no tiene artilleros; sólo tiene cuidadores de ganado, conductores y carreteadores. Análogamente puede decirse de las tropas de zapadores pontoneros y comunicaciones." (Savio 1972 [1933], 41-42). 
armada y de la soberanía económica ${ }^{25}$. Es este anudamiento de ambos problemas el que no aparecía como evidente en los años anteriores a la guerra y el que, en el debate con el que abrí el segundo apartado, le resultaba ajeno al coronel Zerda y a tras luz del cual quedaba ubicado en otra temporalidad que la del resto de sus interlocutores.

De todos modos, tampoco resulta aconsejable una caracterización cerrada en este punto del ethos militar de gobierno. Por esos mismos años, la sensación de un agotamiento del modelo de organización económico liberal, resultaba algo identificable tanto en las políticas públicas de los gobiernos como en los debates intelectuales ${ }^{26}$. Junto a esto, los proyectos de impuesto a la renta de 1918 y 1923, así como la ley de aduana de 1923, la cercanía de Alvear con la Unión Industrial Argentina, las posiciones de un saber económico experto y de estilo reformista, aún no consolidado pero con creciente ascendencia sobre la conducta estatal en materia económica, así como la presencia en el país de algunos referentes internacionales de una visión regulatoria y progresiva en materia de política fiscal así como proteccionista en cuanto a política exterior (Bacolla, 2013), terminan por formar un gran espacio relativamente familiar y de contención en el que tales diagnósticos y prescripciones no habrían resultado del todo extraños ${ }^{27}$.

Con todo, si no es posible una lectura insular de las reflexiones económicas de los cuadros militares de la década de 1920, tampoco resulta muy satisfactorio hipotetizar su subsidiariedad respecto del clima de ideas reinante en esos años. En el fondo, las preocupaciones y los problemas son lo suficientemente diferentes como para dinamitar cualquier origen común. Leídas en sus correspondientes genealogías, parece ser más bien el caso de un múltiple nacimiento de un modo de reflexión que anuda la serie Estado-Economía-Industria, sobre el fondo de "un discurso oficial sobre la responsabilidad del Estado para lograr el bienestar general" (Caravaca, ob. cit.: 69). Enfoques y actores (civiles y militares) que habrán de articularse en forma inestable en las décadas de 1930 y 1940, pueden aún reconocerse en la década de 1920 como externos unos de otros.

\section{Conclusión}

Por medio de la identificación de un modo de problematización singular - la irrupción de un objeto del pensamiento en el marco de alguna coyuntura crítica, su disposición en un plano de ordenamiento junto a otros objetos, su vinculación a juicios de estrategia política o de relevancia moral, etc. - he tratado de argumentar que la primera guerra mundial representó precisamente una coyuntura crítica para el pensamiento militar, y fue el acontecimiento que permitió que el comportamiento económico del Estado irrumpiese como un asunto del cual caben formular preguntas y diagnósticos, fenómeno hasta ese momento inexistente.

El drama bélico derivó en la existencia de dos elementos que fueron juzgados como incompatibles. Se trata por un lado del esquema de división y coordinación internacional del trabajo que asignaba a la Argentina un lugar específico en su rol de economía agroexportadora, por el otro, la percepción de una necesaria organización industrial robusta a los fines de proveer de modo directo e indirecto, los

25 Nada similar aparece en los estudios más generales del pensamiento económico en la Argentina de principios del siglo XX. Para algunas referencias, Fernández López $(2000,2002)$ reconstruyó procesos de lectura y recepción más vinculados a la escuela neoclásica. Frid y Lanciotti (2008) hicieron otro tanto respecto de las ideas proteccionistas y corporativistas de economistas italianos en los espacios académicos locales (Universidad de Buenos Aires y Universidad Nacional del Litoral). Caravaca y Plotkin (2007) estudiaron los procesos de profesionalización de la economía y de los economistas, en el marco más general del cambio de su posición de analistas a formuladores de políticas y gestores de gobierno (ob. Cit. 401).

26 En escala europea, cabe recordar al menos como emblema las conferencias de Keynes de 1925, The end of Liberalism. A nivel local, el trabajo recién referenciado de Laura Frid y Norma Lanciotti es muy instructivo respecto a las reflexiones criollas derivadas de la recepción de un pensamiento económico corporativista y estatal-planificador.

27 La Revista de Economía Argentina, una de las publicaciones de mayor peso en el campo económico local, estaba tomando rumbos similares. Jimena Caravaca afirma que se había convertido en los años veinte "en un espacio privilegiado para la difusión de la doctrina industrializadora. Desde el inicio mismo de la publicación puede seguirse una clara línea editorial: la emancipación nacional vendría de la mano del abandono del modelo agroexportador, para pasar a una industrialización ligada a las materias primas locales (Caravaca, 2011: 75). Alejandro Bunge (director de la revista) había publicado en 1920 "Los problemas económicos del presente" y se había convertido, de acuerdo a González Bollo, en un referente a escuchar sobre las necesarias reformas al modelo agroexportador (González Bollo, 2012: 59). Ver además y entre otros, Audino, ob. cit.; Caravaca, 2005, 2011 y 2016; Blanco, Cerra y Lucchini. 2002; 2014; Jáuregui y Regalsky, ob. cit.; Padín, 2015; Regalsky 2013. 
fundamentos de una defensa armada en la nueva era de las guerras industriales. Tal disyuntiva es la que se organizó de manera explícita en el mundo militar desde la década del '20.

Las preocupaciones que nacieron al calor de un diagnóstico sobre la propia situación del ejército y el modo de afrontarla, en pocos años dieron paso a consideraciones sobre el rol del Estado en la planificación de las actividades económicas y específicamente sobre el apoyo que debía prestar a la consolidación de una base industrial. Sin dudas que todo esto debería ser confrontado y enriquecido con otros trabajos que permitan sopesar la hipótesis de este ingreso del Estado en las reflexiones militares.

En general, el plano reflexivo de los cuadros militares argentinos no ha sido interpretado como un objeto de relevancia que permita enriquecer la gama de percepciones y experiencias con la que los actores colectivos e individuales daban sentido a su mundo económico. Quizá nos hayamos privado de ese modo de la consideración de algunos antecedentes sobre la conducta económica del Estado, en las décadas siguientes. De ser así, este pequeño trabajo podría ser visto como un gesto que pondera dicha situación.

\section{Bibliografía}

Albert, Bill. [1988] 2009 South America and the First World War. The impact of war on Brazil, Argentina, Peru and Chile, Cambridge: Cambridge University Press, DOI: https://doi.org/10.1017/CBO9780511529184

Audino, Patricia. 2004. "La influencia de las ideas económicas en las políticas de la Argentina de principios de siglo XX". Estudios Económicos, 21, 42, Bahía Blanca. Disponible en http://bibliotecadigital.uns. edu.ar/scielo.php?script $=$ sci arttext\&pid $=$ S2525-12952004001100001\&lng $=$ en\&nrm $=$ iso

Balderston, Theo. 2010. Industrial Mobilization and War Economies. En John Horne (Ed.) A Companion to World War I, Chichester (Reino Unido), Wiley-Blackwell, pp. 217-233. DOI: https://doi. org/10.1002/9781444323634.ch15

Blanco, Teodoro, Cerra Ángel y Lucchini, María Cristina. 2002. El pensamiento industrialista argentino en el periodo de entreguerras, el estudio de un caso: la influencia de List en Bunge. Estudios Interdisciplinarios de América Latina y el Caribe, Vol. 11, Núm. 2. Disponible en: http://eial.tau.ac.il/ index.php/eial/article/view/1005/1040

Brambila, Berta, Love, Joseph y Martínez, Andrea. 1980. Raúl Prebisch y los orígenes de la doctrina del intercambio desigual, en Revista Mexicana de Sociología, 42 (1), 375-405. DOI: https://doi. org/10.2307/3540039

Blanco, Teodoro, Cerra, Ángel y Luchini, María Cristina. 2002. La discusión sobre el desarrollo en el periodo de entreguerras: la perspectiva argentina y canadiense, en Memorias de las Terceras Jornadas de historia Económica, 548-557. Disponible en http://nulan.mdp.edu.ar/2367/1/lucchini.etal.2002.pdf

Caravaca, Jimena. 2005. La ciencia económica argentina. Institucionalización, difusión y legitimación, 2-17, X Jornadas Departamentos/Interescuelas de Historia.

- 2011. ¿Liberalismo o intervencionismo? Debates sobre el rol del Estado en la economía argentina. 1870-1935, Buenos Aires: Editorial Sudamericana.

Caravaca, Jimena y Plotkin, Mariano. 2007. Crisis, ciencias sociales y elites estatales: la constitución del campo de los economistas estatales en la Argentina. Desarrollo Económico, Vol. 47, Núm. 187, 401428. Disponible en: http://www.jstor.org/stable/20066806

Caravaca, Jimena y Espeche, Ximena. 2016. América Latina como problema y como solución: Robert Triffin, Daniel Cosio Villegas, Víctor Urquidi y Raúl Prebisch antes del Manifiesto latinoamericano (1944-1946). Desarrollo Económico, Vol. 55, Núm. 217, 411-435. Disponible en http://www.jstor.org/ stable/44736035

Círculo Militar. Revista Militar. Años 1914, 1915, 1916, 1919, 1920, 1921, 1922, 1923, 1926, 1927, 1933 , 1934

Círculo Militar. Revista del Suboficial. Año 1922, 1923. Biblioteca Nacional Militar.

Crespo, Jorge. 1919. Geografía Económica del Brasil, Buenos Aires, Talleres Gráficos del Instituto Geográfico Militar.

- 1924. El problema de la aeronáutica en el país (como factor económico y de defensa nacional). Buenos Aires: Taller Gráfico L. Bernard. 
Cornut, Hernán (2018) "Pensamiento, profesionalización militar y conflicto en el Ámbito del ABC a Principios del siglo XX”. Revista PolHis, Año 10, Núm. 20, 127-160. Disponible en http://polhis.com. ar/index.php/PolHis/article/view/268/505074

Daiçková, Eva 2014. "El ejército argentino como factor económico". Tesis doctoral presentada en Univerzita Karlova v Praze, Filozofická fakulta. Disponible en: https://dspace.cuni.cz/handle/20.500.11956/72953

Dick, Enrique. 2014. La profesionalización en el Ejército Argentino (1899-1914). Buenos Aires: Académica Nacional de Historia.

Echagüe, Selva. 1999. Savio. Acero para la industria. Buenos Aires: Editorial María Ghirlanda.

Escuela Superior de Guerra. Estudios y Comunicación de Información (Revista), años 1923, 1925. Biblioteca Nacional Militar.

Fernández López, Manuel 2000. Cuestiones económicas argentinas, Buenos Aires: A-Z.

- 2002 "Hugo Broggi y la escuela de Lausana", en Anales de la Academia Nacional de Ciencias Económicas Ed. 47, Buenos Aires: Academia Nacional de Ciencias Económicas, 71-102.

Forte, Riccardo. 2003. Militares, cultura política y proyecto económico en la Argentina de la primera mitad del siglo XX. Anuario de Historia Regional y de las Fronteras, Vol. VIII, 335-368. Disponible en http:// historiapolitica.com/datos/biblioteca/Forte2.pdf

García Molina, Fernando. 2010. La prehistoria del poder militar en la Argentina. La profesionalización, el modelo alemán y la decadencia del régimen oligárquico. Buenos Aires: Eudeba.

Gerchunoff, Pablo. 2016. El eslabón perdido. La economía política de los gobiernos radicales (19161930). Buenos Aires: Edhasa.

Gonzalez Bollo, Hernán. 2012. La visión macroeconómica de Alejandro Bunge: construcción de un modelo estadístico (Argentina, 1913-1920), 57-77, Estadistica e Sociedade, N 2. Disponible en http://seer. ufrgs.br/index.php/estatisticaesociedade/article/view/36556/23653

Jáuregui, Aníbal y Regalsky, Andrés. 2003. Americanización y proyecto económico: una aproximación a las ideas de Alejandro Bunge en los años '20. En Americanización: aspectos culturales, económicos y tecnológicos de la transferencia de un modelo. Los Estados Unidos y América Latina en el siglo XX, Buenos Aires: Editorial de la Universidad de Tres de Febrero, pp. 71-99

Love, Joseph. (1990) The Origins of Dependency Analysis, Journal of Latin American Studies, Vol. 22 (12), 143-168. DOI: https://doi.org/10.1017/S0022216X00015145

- 2008. Economics ideas and ideologies in Latin America since 1930, en Leslie Bethell (Ed.), The Cambridge History of Latin America, Vol. 1, Cambridge, Cambridge University Press, pp. 391-460. DOI https://doi.org/10.1017/CHOL9780521232265.008

Mallorquín, Carlos (1998) Ideas e historia en torno al pensamiento económico latinoamericano, México: PyV Editores.

Ministerio de Guerra. Memorias del Ministerio de Guerra, 1924. Biblioteca Nacional Militar.

Mosconi, Enrique. 1923. Dos informes sobre la explotación del petróleo de Comodoro Rivadavia, Buenos Aires, L. J. Rosso y Cía. Impresiones.

- 1936. El petróleo argentino, 1922-1930. Y la ruptura de los trust petroliferos inglés y norteamericanos el 1 de agosto de 1929, Buenos Aires, Círculo Militar.

- 1939. Dichos y Hechos, 1904-1938, Buenos Aires: Librería y Editorial El Ateneo.

Munilla, Eduardo. 1916. La defensa Nacional. Ideas y conceptos que la inspiran, Buenos Aires, Librería La Facultad.

Orestes, Popescu. 2003. Studies in the History of Latin American Economic Thought, Londres y Nueva York: Routledge.

Otero, Hernán. 2011. Emigración, movilización militar y cultura de Guerra. Los franceses de la Argentina durante la Gran Guerra. Revue de civilisation contemporaine Europes/Amériques, Núm. 10. DOI: $10.4000 /$ amnis. 1137

Padín, Nicolás. 2015. "Industria temprana", modelo agro-exportador y los orígenes del pensamiento industrial en Argentina: Alejandro Bunge, 1880-1930. Cuadernos de Investigación, Serie Economía, $\mathrm{N}^{\circ}$ 5, 33-49. Disponible en: http://revele.uncoma.edu.ar/htdoc/revele/index.php/cuadernos/article/ view/1087

Potash, Robert. 1971. El ejército y la política en la Argentina, Tomo I, 1928 - 1945. De Yrigoyen a Perón, Buenos Aires: Hyspamerica.

Porte, Remi. 2005. La movilisation industrielle, 'premier front'de la Grand Guerre?, Paris: 14-18 Editions. 
- 2006. "Mobilisation Industrielle et guerre totale: 1916, année charniére", 1-10, Revue Historique des armées, $\mathrm{N}^{\circ}$ 242. Disponible en http://journals.openedition.org/rha/4072

Regalsky, Andrés. 2013. Los comienzos de la industrialización en la Argentina, 1880-1930. Una aproximación historiográfica, 75-106, Revista Digital N².

Rouquié, Alain. 1984. El estado militar en América Latina, Buenos Aires: emecé,.

- 1986. Poder militar y sociedad política en la Argentina, Tomo I, Buenos Aires: Hyspamerica.

Savio, Domingo. 1932. [Traducción] Tecnología mecánica, Tolerancias, Normas Italianas, Tiempos de Trabajo; Medios de Control, Buenos Aires, Talleres Gráficos del Colegio Militar.

- 1972. Obras del General Savio. Buenos Aires, SOMISA.

Scenna, Miguel Ángel. 1980. Los militares, Buenos Aires: Editorial de Belgrano.

Tato, María Inés. 2008. La disputa por la argentinidad. Rupturistas y neutralistas durante la Primera Guerra Mundial. Temas de historia argentina y americana, Núm. 13, 227-250.

Disponible en http://bibliotecadigital.uca.edu.ar/repositorio/revistas/temas-de-historia13.pdf

- 2011. El llamado de la Patria. Británicos e italianos residentes en la Argentina frente a la Primera Guerra Mundial. Estudios Migratorios Latinoamericanos, Núm. 71, 273-292.

- 2014.LaGranGuerraenlahistoriografíaargentina. Balanceyperspectivasdeinvestigación.Iberoamericana (2001-), 14(53), 91-101. Disponible en http://www.jstor.org/stable/24368637

- 2017. La Trinchera Austral. La sociedad argentina ante la Primera Guerra Mundial, Rosario: Prohistoria.

Yelpo, José .1987. Ejército, política, proyecto alternativo 1920-1943, Buenos Aires: Talleres Gráficos de Roslfo Stang.

Vicente, Martín. 2013. 'Los furores de una demagoga destructora': sociedad de masas, liderazgo político y estado en la trayectoria político-intelectual de Federico Pinedo. Nuevo Mundo, Nuevos Mundos. DOI: 10.4000/nuevomundo.65654

Wozniak, Dominika. 2014. Latin American 19th. Century Economic Debate as the Predecessor of the CentrePeriphery and Dependency Theories: The Case of Argentina. Cesla, Núm. 17, 181-199. Disponible en http://www.redalyc.org/articulo.oa?id=243333483009 
